Review began 09/05/2021 Review ended 09/08/2021 Published 09/19/2021

๑) Copyright 2021

Katiyar et al. This is an open access article distributed under the terms of the Creative Commons Attribution License CC-BY 4.0., which permits unrestricted use, distribution, and reproduction in any medium, provided the original author and source are credited.

\section{Polycythemia in a Patient With Atonic Bladder and Hydronephrosis}

\author{
Vatsala Katiyar $^{1}$, Talha Aijaz ${ }^{1}$, Prasanth Lingamaneni ${ }^{2}$, Ishaan Vohra ${ }^{3}$, Kamila Cisak ${ }^{1}$ \\ 1. Division of Medical Oncology and Hematology, Department of Internal Medicine, James Graham Brown Cancer \\ Center, University of Louisville School of Medicine, Louisville, USA 2. Department of Internal Medicine, John H. \\ Stroger, Jr. Hospital of Cook County, Chicago, USA 3. Division of Gastroenterology, Department of Internal Medicine, \\ University of Illinois College of Medicine at Peoria, Peoria, USA
}

Corresponding author: Vatsala Katiyar, vatsala.katiyar@gmail.com

\begin{abstract}
Kidneys influence the production of red blood cells by secreting most of the erythropoietin (EPO) in adults. Consequently, renal diseases often impact erythropoiesis and hemoglobin levels. Chronic kidney diseases lead to anemia due to EPO deficiency. However, erythrocytosis can occur in patients with cystic diseases of the kidney and renal artery stenosis due to upregulation of hypoxia-inducible factors (HIFs) and increased EPO production. Here, we present a patient with secondary polycythemia who was found to have atonic bladder and hydronephrosis. Resolution of hydronephrosis led to the reversal of erythrocytosis, highlighting the intricate regulation of red cell production.
\end{abstract}

Categories: Internal Medicine, Nephrology, Hematology

Keywords: polycythemia, hypoxia inducible factor, erythropoietin, hydronephrosis, secondary erythrocytosis, secondary polycythemia

\section{Introduction}

Polycythemia is a state of abnormally elevated red blood cell mass defined as hemoglobin $>16.5 \mathrm{~g} / \mathrm{dL}$ in men and $>16.0 \mathrm{~g} / \mathrm{dL}$ in women or a hematocrit $>49 \%$ in men and $>48 \%$ in women [1]. Secondary erythrocytosis occurs in instances of tissue hypoxia or inappropriate autonomous erythropoietin (EPO) secretion by tumors. Renal diseases also lead to polycythemia by upregulating EPO production when the oxygen sensing mechanism is impaired [2]. Here, we report a patient with hydronephrosis and polycythemia whose hemoglobin normalized after resolution of hydronephrosis.

\section{Case Presentation}

A 60-year-old male was referred to hematology clinic for erythrocytosis. A month before the clinic appointment, he experienced a motor vehicle accident (MVA) and went to the emergency room (ER), where elevated hemoglobin was first detected. He had not seen a physician in many years prior to the MVA.

Laboratory values during the ER visit are reported in Table 1 . There was no evidence of acute traumatic injury on whole-body computed tomography, but it showed a markedly distended urinary bladder with severe bilateral hydronephrosis concerning outflow obstruction (Figures $1 A, 1 B$ ). He was discharged with a foley catheter and urology follow-up. On a repeat kidney ultrasound, bilateral hydronephrosis had decreased (Figures 2A, 2B). Prostate-specific antigen (PSA) was normal, and cystoscopy did not reveal any evidence of malignancy. He was diagnosed with idiopathic atonic bladder and was advised to continue intermittent catheterization. The patient continued to have persistent erythrocytosis with subsequent hemoglobin being $20.4 \mathrm{~g} / \mathrm{dL}$ and $19.2 \mathrm{~g} / \mathrm{dL}$. 


\section{Cureus}

\begin{tabular}{|c|c|c|c|}
\hline Lab parameters & Values in ER & Values in hematology clinic & Reference range \\
\hline Hemoglobin & 20.7 & 18.7 & $7-18 \mathrm{~g} / \mathrm{dL}$ \\
\hline Hematocrit & 59.1 & 54.1 & $40-51 \%$ \\
\hline White blood cells & 6.8 & 6.5 & $4.1-10.8 \mathrm{k} / \mathrm{uL}$ \\
\hline Platelets & 200 & 219 & 140-370 k/uL \\
\hline Creatinine & 1.61 & 1.40 & $0.64-1.27 \mathrm{mg} / \mathrm{dL}$ \\
\hline Lactate dehydrogenase & - & 169 & $100-242$ U/L \\
\hline Erythropoietin & - & 3.3 & $2.6-18.5 \mathrm{mlU} / \mathrm{mL}$ \\
\hline
\end{tabular}

TABLE 1: Pertinent laboratory values.

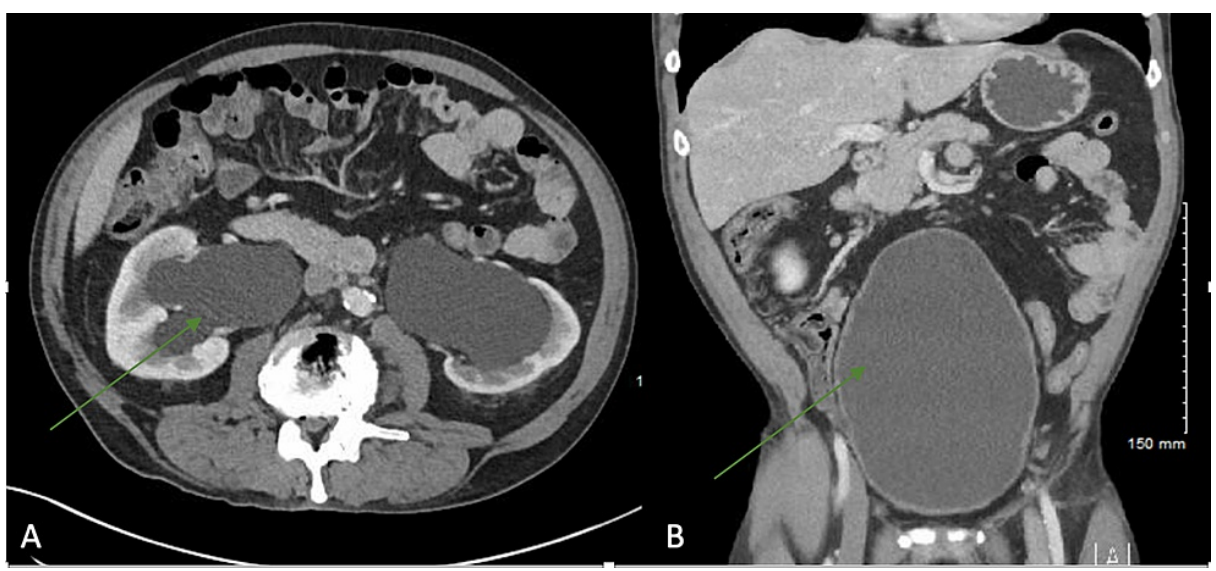

FIGURE 1: Computed tomography scan of abdomen of (A) axial and (B) coronal sections showing hydroureteronephrosis and distended bladder.

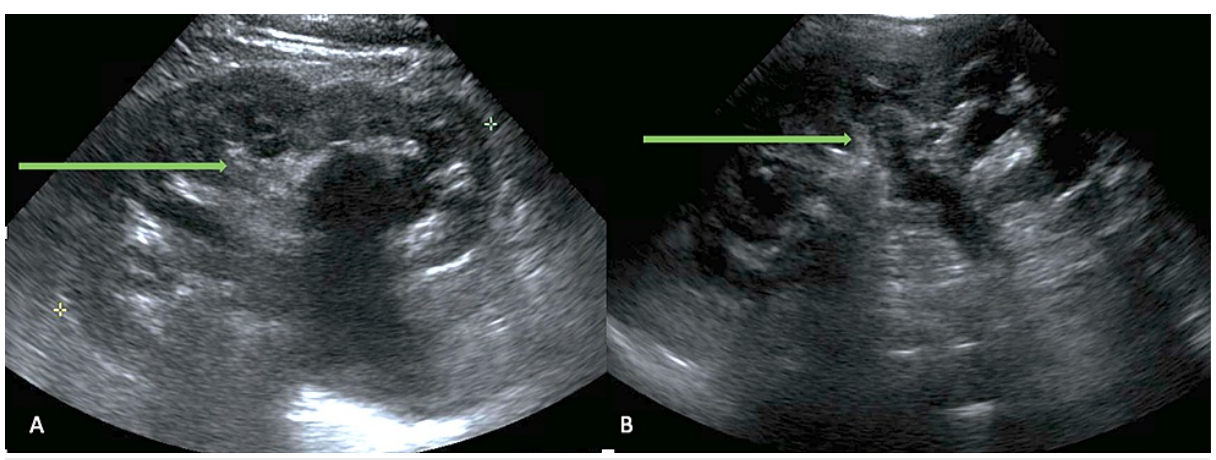

FIGURE 2: Ultrasound (sagittal view) of left kidney (A) and right kidney (B) showing improvement in hydronephrosis.

During his hematology clinic visit, he only reported lower urinary tract symptoms and required intermittent catheterization. He denied dizziness, headaches, pruritis, erythromelalgia, night sweats, fevers, vomiting, diarrhea, weight loss, and previous blood clots. He did not use any over-the-counter medications or anabolic steroids. There was no family history of blood disorders. He had a 40-pack year smoking history and reported chronic alcohol use. His body mass index was $23.6 \mathrm{~kg} / \mathrm{m}^{2}$, and there were no symptoms suggestive of obstructive sleep apnea. Laboratory workup during the hematology visit is detailed in Table 1. Peripheral blood smear showed erythrocytosis with no abnormal cell morphology. Since the EPO level was at the lower 


\section{Cureus}

end of normal, JAK2 V617F, JAK2 exon 12-14, CALR, MPL mutations were sent but not detected.

He was advised to quit smoking, but unfortunately, he continued to smoke. At a subsequent two-month follow-up, his hemoglobin had down trended to $14.7 \mathrm{~g} / \mathrm{dL}$, and at six-month follow-up, it was $15.8 \mathrm{~g} / \mathrm{dL}$. There was no evidence of bleeding. Other cell lines continued to stay within normal limits. Repeat kidney ultrasound showed normalization of kidney size (Figure 3A, 3B). He was deemed to have polycythemia secondary to local renal ischemia induced by renal tubular compression in the setting of hydronephrosis.

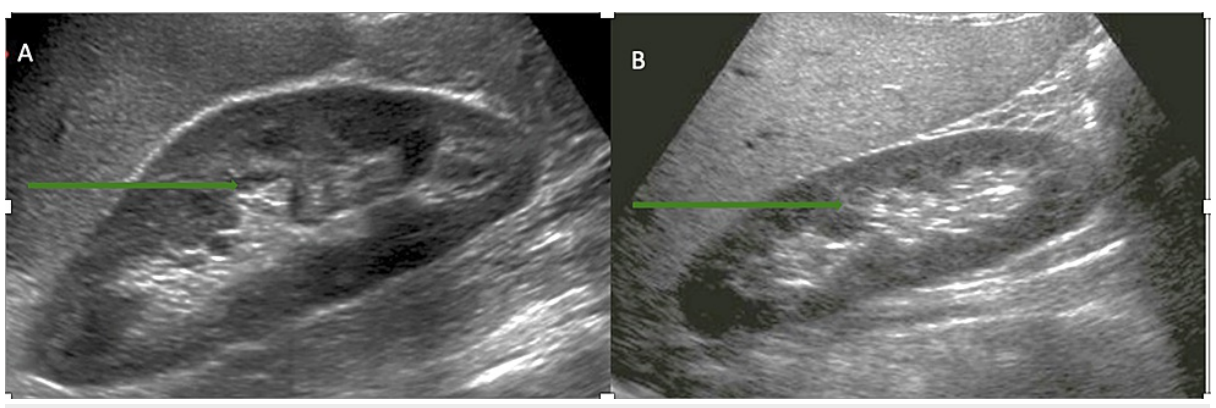

FIGURE 3: Ultrasound (sagittal view) of left kidney (A) and right kidney (B) demonstrating resolution of hydronephrosis.

\section{Discussion}

Hypoxia-driven erythrocytosis is associated with increased EPO production as opposed to polycythemia vera, where EPO levels are characteristically low [2]. EPO is a glycoprotein hormone composed of a single 165 amino acid residue chain linked to four glycans and is primarily secreted by the peritubular fibroblasts in the renal cortex [3]. EPO gene expression is tightly regulated by a complex mechanism involving hypoxiainducible factors (HIF). As the blood oxygen concentration declines, the ubiquitination and proteasomal degradation of HIF-1 decreases, thereby raising its levels. It binds to a cis-acting hypoxia response element present at the 3" flanking region of the human EPO gene. In turn, the elevation in HIF-1 leads to increased transcription of the EPO gene and a rise in its levels. Erythropoietin binds to its receptor on the erythroid progenitor cells, which initiates the signal transduction cascade and ultimately stimulates the survival, proliferation, and differentiation of erythroid precursors $[4,5]$.

Increased HIF and consequent high EPO levels can occur in instances of true hypoxia from chronic pulmonary disease, right to left cardiac shunts, sleep apnea and chronic carbon monoxide poisoning, or compromised oxygen detection due to diseases intrinsic to the kidney such as renal artery stenosis, cysts and hydronephrosis [2]. In addition, inappropriate autonomous EPO production by tumors like hepatocellular carcinoma, renal cell carcinoma, and pheochromocytoma can also lead to secondary erythrocytosis [2].

Our patient had erythrocytosis as well as severe hydroureteronephrosis and atonic bladder on presentation. He started intermittent self-catheterization, which led to the resolution of hydronephrosis and a decline in hemoglobin levels. The proposed mechanism for polycythemia in hydronephrosis is intrarenal hypoxia caused by tubular compression, which is reversed with the withdrawal of the stimulus [6]. Interestingly, in a patient with leukemic infiltration of the kidney and secondary polycythemia, increased HIF 1a expression has been demonstrated in kidney cells, suggesting that renal tubules become ischemic when compressed and stimulate EPO synthesis [7].

In addition to kidney disease, our patient had a significant smoking history, which is known to cause erythrocytosis through multiple mechanisms. Smoking not only leads to chronic lung disease and increased carbon monoxide levels causing absolute polycythemia, but it also triggers volume contraction giving rise to relative polycythemia [8]. However, our patient did not have any history or imaging findings suggestive of lung disease, and his hemoglobin levels decreased despite persistent smoking, prompting us to look for other etiologies.

As EPO level was at the lower end of normal, there was concern about polycythemia vera. Hence, JAK2 V617F and JAK2 exon 12-14 mutations testing was done. Bone marrow biopsy was deferred as he did not have detectable mutations and hematocrit normalized. Consequently, we concluded that his erythrocytosis was in fact, related to hydronephrosis.

\section{Conclusions}

Even though hydronephrosis is a common diagnosis, its association with secondary erythrocytosis is not usually seen in clinical practice. The amount of residual non-ischemic renal tissue could play a role in the infrequent occurrence of the two conditions together. Moreover, other pathways apart from tubular 
compression and HIF upregulation could contribute to polycythemia in patients with hydronephrosis and need further investigation.

\section{Additional Information \\ Disclosures}

Human subjects: Consent was obtained or waived by all participants in this study. Conflicts of interest: In compliance with the ICMJE uniform disclosure form, all authors declare the following: Payment/services info: All authors have declared that no financial support was received from any organization for the submitted work. Financial relationships: All authors have declared that they have no financial relationships at present or within the previous three years with any organizations that might have an interest in the submitted work. Other relationships: All authors have declared that there are no other relationships or activities that could appear to have influenced the submitted work.

\section{References}

1. Tefferi A, Barbui T: Polycythemia vera and essential thrombocythemia: 2019 update on diagnosis, riskstratification and management. Am J Hematol. 2019, 94:133-43. 10.1002/ajh.25303

2. Patnaik MM, Tefferi A: The complete evaluation of erythrocytosis: congenital and acquired . Leukemia. 2009, 23:834-44. 10.1038/leu.2009.54

3. Jelkmann W: Physiology and pharmacology of erythropoietin. Transfus Med Hemother. 2013, 40:302-9. $10.1159 / 000356193$

4. Semenza GL: Involvement of oxygen-sensing pathways in physiologic and pathologic erythropoiesis . Blood. 2009, 114:2015-9. 10.1182/blood-2009-05-189985

5. Beck I, Ramirez S, Weinmann R, Caro J: Enhancer element at the 3'-flanking region controls transcriptional response to hypoxia in the human erythropoietin gene. J Biol Chem. 1991, 266:15563-6.

6. Jaworski ZF, Wolan CT: Hydronephrosis and polycythemia. A case of erythrocytosis relieved by decompression of unilateral hydronephrosis and cured by nephrectomy. Am J Med. 1963, 34:523-34. 10.1016/0002-9343(63)90075-5

7. Osumi T, Awazu M, Fujimura E, Yamazaki F, Hashiguchi A, Shimada H: Leukemia kidney infiltration can cause secondary polycythemia by activating hypoxia-inducible factor (HIF) pathway. Eur J Pediatr. 2013, 172:829-32. 10.1007/s00431-013-2030-7

8. Smith JR, Landaw SA: Smokers' polycythemia. N Engl J Med. 1978, 298:6-10. 10.1056/NEJM197801052980102 